\title{
Determinant Factors Affecting Crop Production and Adoption of Soil and Water Conservation Practices In Semein Mountain National Park, Ethiopia
}

\author{
Mohammed Gedefaw ${ }^{1,3 *}$, Yan Denghua ${ }^{2}$, Wang $\mathrm{Hao}^{2}$, Basaznew Alemu ${ }^{3}$, Mersha Chanie ${ }^{3}$ and Genanew Agitew ${ }^{3}$ \\ ${ }^{1}$ College of Environmental Science, Engineering, Donghua University, China \\ ${ }^{2}$ State Key Laboratory of Simulation and Regulation of Water Cycle in River Basin, China Institute of Water Resource and Hydropower Research, China \\ ${ }^{3}$ University of Gondar, Ethiopia
}

Submission: June 13, 2018; Published: July 10, 2018

*Corresponding author: Mohammed Gedefaw, College of Environmental Science \& Engineering, Donghua University, China, Email: mohammedgedefaw@gmail.com

\begin{abstract}
This study was undertaken to investigate the determinant factors affection the adoption of SWC measures in semein mountain national park. Case study areas were selected based on proximity to the park and from high-potential and low-potential sites. A simple random sampling method was employed to select a sample of 150 household farmers using face to face interviews, focus group discussions, key informants and field observations. The binary logistic regression model and descriptive statistics were used to analyze the data. The results showed that $76 \%$ of the sampled farmers used SWC structures. The sustainable adoption of SWC measures seems unlikely due to physical, institutional and socioeconomic factors. In addition, absence of clear understanding of the benefits of SWC structures by farmers, technical support from the government, and genuine participation of farmers in SWC practices were found to be main factors in the adoption of SWC measures. Thus, policy makers should take into consideration the determinant factors affecting adoption of SWC when designing and implementing introduced SWC measures.
\end{abstract}

Keywords: Adoption; Soil and Water Conservation; Determinant; Semein Mountaion National Parks; Policy Intervention

\section{Introduction}

Ethiopia is an agrarian country where its economy mainly dependent on agriculture which is dominated by subsistence smallholder farmers that are partially integrated into markets. The fate of the agricultural sector directly affects the economic development, food security, and poverty alleviation. However, the role of this sector in alleviating poverty and food insecurity is undermined by land degradation such as soil erosion and nutrient depletion [1-5]. Studies showed that $50 \%$ of Ethiopian highlands have significant soil erosion, $25 \%$ of it was highly eroded and $4 \%$ of is seriously eroded beyond reclamation $[1,6,7]$. These problems become more worse in Amhara regions where about $90 \%$ of its population lives in the highland areas which constitute $66 \%$ of its total land area. Out of which, $90 \%$ of this land is regularly cultivated, which exposes it to soil erosion [8]. The government of Ethiopia promoting the soil and water conservation (SWC) technologies for improving agricultural productivity over the last four decades. However, smallholder farmers' agriculture in the country is characterized by widespread failure to make adequate SWC and soil replenishment investments in order to sustain the productivity of farmlands $[3-5,9,10]$. Investigating the determinant factors that affects farmers' adoption behavior is therefore important for designing policies that could stimulate and sustain adoption of SWC and agricultural productivity. The adoption of SWC technologies is imperious to enhance crop yield and ameliorate the livelihoods of farmers [11]. Effective SWC technologies have been tested through projects and the endogenous knowledge of agriculturists. It is imperative to create favorable conditions so that a greater number of farmers can take advantage of these technologies [4].

In this study, physical, socio-economic and institutional determinant factors for adoption of SWC technologies in SMNP were identified. Considering that fact, this study is intended to revisit sustainable land management technology trough 
adoption of SWC technologies in SMNP and to investigate how they have improved community livelihood, more particularly on income and food security. Findings on the level to which these aspects influence the adoption of soil and water control technologies can help in the expansion of locally appropriate soil and water control technologies and methods.

\section{Materials and Methods}

\section{Description of the Study Area}

Simien Mountains National Park (SMNP) is located in the North Gonder Zone of the Amhara National Regional State,
$920 \mathrm{~km}$ north of Addis Ababa. It lies between $13^{\circ} 09^{\prime}$ and $13^{\circ} 12^{\prime} \mathrm{N}$ and $38^{\circ} 00^{\prime}$ and $38^{\circ} 12^{\prime} \mathrm{E}$ [12] (Figure 1). The altitude of SMNP ranges from 1,900 to $4,543 \mathrm{~m}$. It has an Afro-alpine undulating grassland plateau with steep escarpments lying towards both the north and east direction, giving spectacular views of peaks and canyons of areas found outside the boundary of the park. There are V- and U-shaped canyons due to geological processes. The rainfall pattern is characterized by a single rainy season, whereby the highest amount of precipitation is between June and September $[6,10,12]$. The average annual rainfall is between 1,350 and $1,550 \mathrm{~mm}$ and varies with altitude. Temperature ranges from -2 to $18^{\circ} \mathrm{C}$.

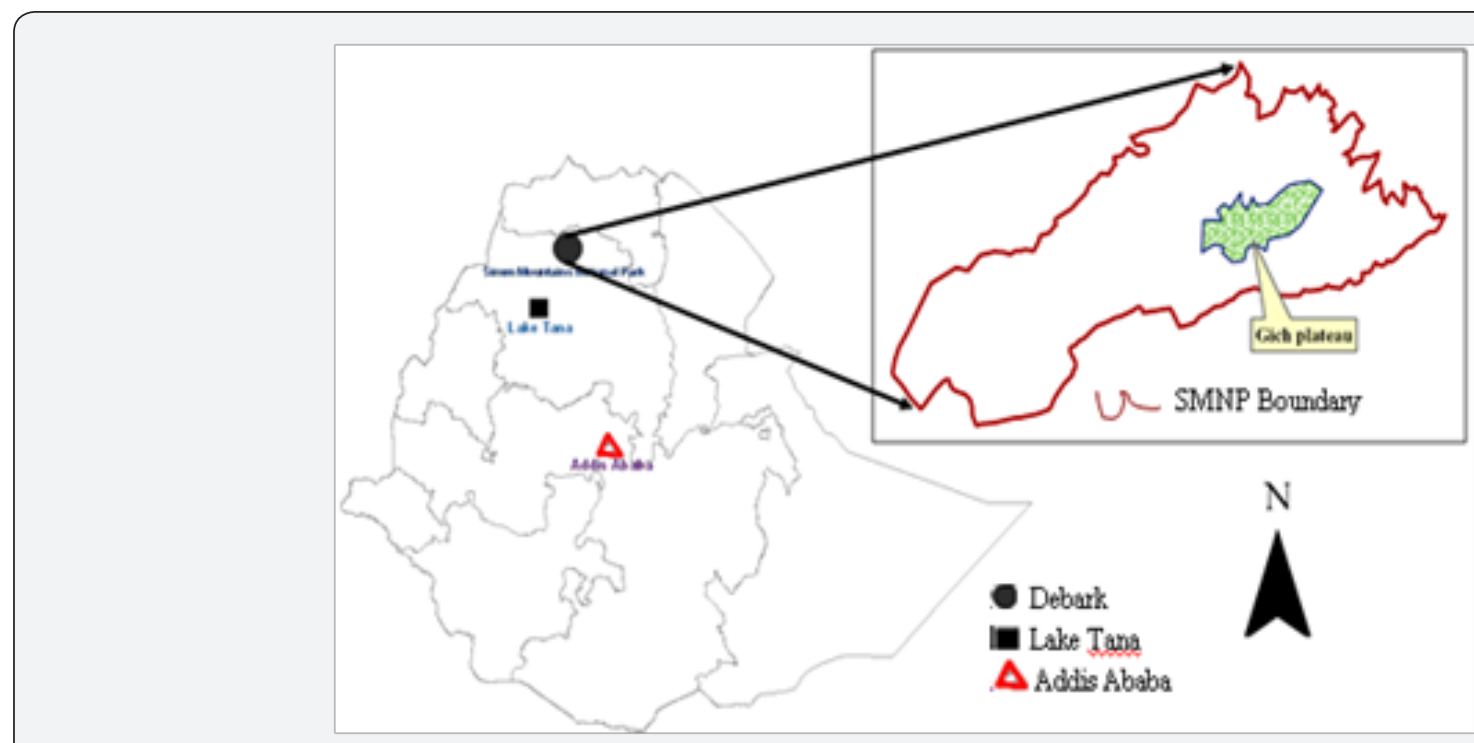

Figure 1: Map of study area.

Due to differences in land use practice, geological events, topography and climate, different soil types are found in the SMNP. Andosol type of soil is found on uncultivated land above $3,000 \mathrm{~m}$, whereas below $3,000 \mathrm{~m}$ and on cultivation land above $3,000 \mathrm{~m}$, the dominant type of soil are Phaeozem, Vertisol, Luvisol, Regosol and Leptosol [10]. The grassland is dominantly covered with Andosol. The very small area, with no agricultural potential is attributed to Fluvisol. When first established in 1966, the Simien Mountains National Park encompassed an area of just $136 \mathrm{~km}^{2}$. A further extension was agreed in 2007, and the park was extended to include the peaks of Silki, Kidus Yared and RasDejen, the highest mountain in Ethiopia. Currently, the total park area is $412 \mathrm{~km}^{2}$. Because of its rich biodiversity, high number of endemic species and special bio-physical features, SMNP is one of the World Heritage Site in the country listed by UNESCO.

\section{Research Design and Methodology}

The quantitative research method enabled to collect data on all quantified relationships between adoption of SWC technologies and determinant factors. Whereas, Qualitative research method was used to collect and analyze qualitative data which were used to strengthen the gap in quantitative research method.

\section{Sampling Technique and Sample Size}

A simple random sampling technique was used to select the sample sizes. SMNP is surrounded by five were das with 38 kebeles. Of which 12 kebeles had a direct contact with the park and these 12 kebeles taken as a sample size to see their impacts on the park and from these kebeles 150 representative households (HHs) were selected and the questionnaire were distributed. Key informants were selected purposely from the agricultural offices, SMNP office, agricultural extension workers, and kebeleadministrators. Based on data saturation, 24 key informants were employed. To develop the farmer's trust in the interviewer, each farmer was well informed about the purpose of the survey and why he/she is chosen for the interview. One enumerator was selected based on their understanding of farming and SWC practices and their educational level for each kebele. One day of intensive training on how to conduct interviews and record information in the questionnaire properly was given. Subsequently interview was conducted by the selected enumerators and the corresponding main researcher. At the end 
of the formal survey in each village, discussions were held by the researcher and the enumerators with key informants including community leaders and development agents. This informal technique is used to acquire useful and detailed information about biophysical factors and farmers' perceptions.

\section{Data Source and Data Collection Techniques}

Questionnaires, in-depth interview, focus group discussion and field observation were used as the primary data collection techniques. Closed and open-ended questions were prepared and distributed to the respondents. The questionnaire enabled to collect data from representative sample household farmers. In-depth interview was also conducted with key informants who were considered knowledgeable about the general situation of SWC practices. Furthermore, the secondary data were collected from the SMNP office, agricultural offices of each kebele, written documents and annual reports about the physical and socioeconomic conditions of the study area.

\section{Data Analysis and Interpretation}

Table 1: Determinant factors that decreases the production of crops in the study area.

\begin{tabular}{|c|c|}
\hline Determinants & Significant impacts \\
\hline Flooding & $0.507(0.603)$ \\
\hline Ice & $6.706(0.002)^{* * *}$ \\
\hline Drought & $1.276(0.283)$ \\
\hline Insects infestation & $0.340(0.713)$ \\
\hline Wind force & $1.761(0.176)$ \\
\hline Inflation & $0.191(0.826)$ \\
\hline Population booming & $0.704(0.496)$ \\
\hline Conflict & $10.411(0.0000)^{* * *}$ \\
\hline Shortage of land & $10.442(0.000)^{* * *}$ \\
\hline Shortage of grazing land & $9.335(0.000)^{* * *}$ \\
\hline
\end{tabular}

Note: ${ }^{* * *}$ indicates, it is statistically significant at $0.01,0.05$ and 0.1 level.

The binary logistic regression method was employed to determine the impacts of independent variables on the dependent variable. It is an appropriate model where the dependent variable is dummy (whether to adopt the strategies to minimize the adverse effects of soil erosion or not, specified as yes $=1,0=$ otherwise). Level of significance was taken at $\mathrm{P}=0.01, \mathrm{P}=0.05$ and $\mathrm{P}=0.1$ levels for analysis. This regression analysis is useful for predicting discrete outcome of dichotomous dependent variable from independent variables that may be continuous, discrete, and/or dichotomous [13]. In this study, the dependent variable is dichotomous variable with value 1 or 0 if a farmer is being perceived (1) or not being perceived (0) climate change. Such data were generated from the questionnaire survey as binary response together with a mixture of discrete and continuous independent variables (Table 1). Logistic regression model was chosen over other models such as discriminant analysis model, because of its advantage in mathematical simplicity to give meaningful results. There are no assumption of normality of independent variables and equal variance within each group in logistic regression [13-15]. However, discriminant analysis can only be used with continuous independent variables keeping the assumptions of normality and equal variance. Hence, since the independent variables of this study are a mix of continuous and categorical, logistic regression is more preferred and statistically robust in practice than discriminant analysis $[13,16]$.

The binary logistic regression function estimated the likelihood of the effects of the independent variables on the dependent variable is described as:

(1)

$$
\ln [\mathrm{p} / 1-\mathrm{p}]=\beta \mathrm{o}+\beta 1 \mathrm{X} 1+\beta 2 \mathrm{X} 2 \beta 3 \mathrm{X} 3+\ldots+\beta \mathrm{kXk}
$$

The quantity $[\mathrm{P} /(1-\mathrm{P})]$ is called the odds (likelihoods) ratio, if $\mathrm{P}$ is the probability for farmers' being perceived climate change, then $1-\mathrm{P}$ represents the probability of not being perceived climate change; $\beta$ is the intercept, $\beta 1, \beta 2, \beta 3 \ldots$ and $\beta \mathrm{k}$ are regression coefficients of the independent variables of $\mathrm{X} 1, \mathrm{X} 2, \mathrm{X} 3 \ldots$ and $\mathrm{Xk}$. If the value of the odds ratio is greater than 1 , the likelihood of the effect of the independent variable on the dependent variable is increased, odds ratio value of one indicates no relationship and a value less than one indicates negative relationship [13].

\section{Results and discussion}

\section{Household Characteristics and Current Status of SWC Measures}

Among household characteristics, the age of the household head influenced the adoption of introduced SWC practices negatively and it was statistically significant at 0.05 level. Because, as the age of a farmer increases, the acceptance of the newly introduced SWC technologies decreased since old farmers do not care about their farmlands. However, young farmers are eager to adopt the newly introduced SWC technologies. Gender of the household heads is also positively correlated with the adoption of introduced SWC practices at statistically significant level. The gender proportions from the total 150 respondents indicated that $90.5 \%$ male and the $9.5 \%$ were female. This showed that male headed households are more likely to be engaged in implementation of SWC practices than female headed households. In line with these, other researchers also confirmed that male headed households have a higher chance to involve in SWC practices than female headed since constructing and maintaining SWC practices demand much labor and energy [8].

\section{Farmers Perception on the Importance of SWC Structures}

This study indicated that almost all farmers used SWC structures in low-potential areas. Although the cultivated land holdings are small one hectare and almost equal to the farm size in the low-potential areas, many farmers of the high-potential areas have not built and maintained physical SWC structures because (1) they do not perceive a significant advantage to their use; instead, SWC reduce crop yields by competing the limited 
ploughing lands and (2) lack of short term economic benefits. Reported that farmers' adoption or non-adoption of SWC structures is significantly affected the perception of farmers soil erosion and its impact. In the high potential areas, the constructed SWC structures improved the productivity of the land after seven years. On the other hand, $[4,6,17,18]$ argued that in high potential areas, physical SWC structures did not have significant impacts on productivity of the land. However, in the long run, physical SWC structures can reduce soil loss and keep the soil in place and improve soil fertility and crop yield and it can regulate and maintain stream and river flows.

\section{Socioeconomic and Institutional Factors and Adoption SWC Practices}

The socioeconomic survey results of this study showed that $76 \%$ the sampled household farmers adopted different types of SWC technologies in their farmlands. As a result, the soil has been improving and enables to grow different types of crops. The SWC structures are a potential to improve ecosystem services in the low potential areas $[1,11,19,20]$. During field observation of SMNP especially in high potential areas soil erosion and gully formation were the common phenomena (Figure 2). However, $65 \%$ of the sampled farmers do not use physical SWC structures and experienced soil and water erosion with serious cases. The binary logistic regression analysis revealed that the size of farmlands cultivated by households had a negative and insignificant impact on farmers' adoption of SWC practices at $95 \%$ with $(\mathrm{p}=0.000)[10,12]$. Reported in their findings a negatively correlation between the size of farmland holding and the probability of adopting soil and water conservation practices. This is may be labor intensiveness to construct the structures in hilly areas.

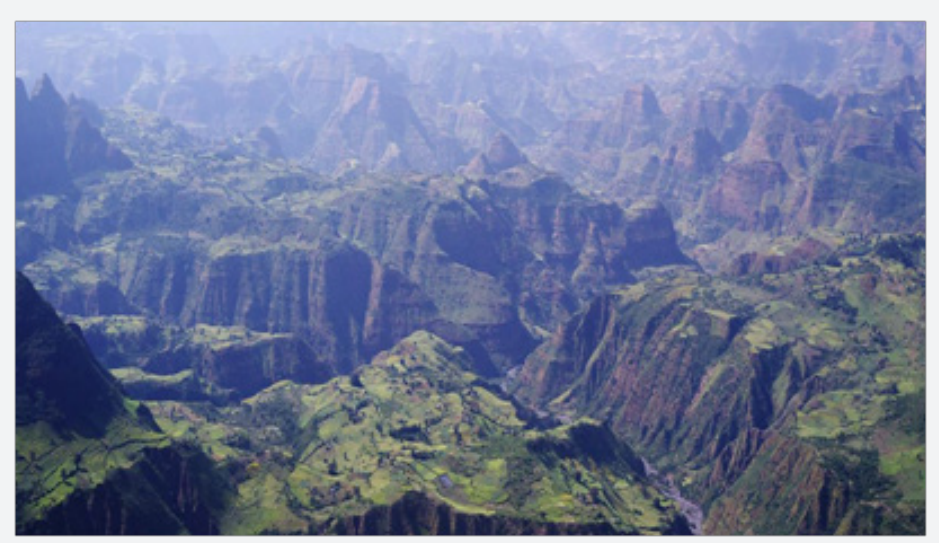

Figure 2: Physical features of SMNP.

Off-farm activity is one of the important socioeconomic factors that influence farmers' acceptance to adopt introduced SWC practices. The result of binary logistic regression analysis depicted that off-farm activity has a negative relationship with the adoption of introduced SWC practices. This is because of labor competition between off farm activity and SWC practices. This result is also supported by [4] who reported that the involvement of farmers in off- farm activity influenced negatively the continued use of SWC practices. Training and agricultural extension services are the basic tools for smallholder farmers to get awareness about SWC and the mechanism how to implement it. Therefore, training and agricultural extension services are the most influential institutional factors for adoption of SWC technologies in SMNP.

\section{Physical Factors and Adoption of SWC Technologies}

Distance of farmland from homestead is negatively correlated with the adoption of introduced SWC technologies since it is difficult to implement and maintain regularly. The respondents replied that this takes time and energy. This is also supported by other researchers. For example $[1,4,8]$ reported that distance between farmlands and household residences correlated significantly and negatively to the adoption of introduced SWC practices [4]. Reported that farm lands far from home do not get much attention from owners since it needs more time and energy for taking care of their farmlands. Similarly, [2] and [4] also confirmed that far away farmlands discouraged adoption of soil and water conservation practices.

\section{Determinant Factors that Affects Crop Production in SMNP}

The result of this study shows that, the reduction of crop productivity since the last two decades was related to drought, flooding, conflict, wind force, ice, insect infestation, inflation, shortage of ploughing land, shortage of grazing land and population growth. The level of significance was tested at $95 \%$ $(\alpha=0.05)$.

\section{Conclusion}

Understanding the determinant factors affecting the adoption of SWC measures is vital for designing an effective policy system that could initiate the adoption of SWC. The study indicates that sample household farmers find themselves in different phases of adoption due to different socio-economic, institutional and 
physical factors. This study identified that perceptions about SWC, labor, and lack of technical support are the obstacles that hinders to adopt SWC by some farmers. Off farm activities are negatively correlated with the adoption of introduced SWC practices. However educational level, age and gender are not statistically significant in influencing the adoption of soil and water conservation practices. The overall result of this paper indicates that physical, institutional and socio-economic factors functioning at different level (national, regional, watershed, farm, and household level play a strong role in shaping farmers' perception and attitude towards adoption of SWC. Thus, policy makers should take into consideration the determinant factors affecting adoption of SWC like human capital (labor force), social capital and technical support when designing and implementing introduced SW technologies. These are achieved through by providing extension and training services on the introduced SWC practices for the farmers. These encourage farmers to take SWC practices on their farmlands.

\section{References}

1. Teshome A, de Graaff J, Kassie M (2016) Household-Level Determinants of Soil and Water Conservation Adoption Phases: Evidence from NorthWestern Ethiopian Highlands. Environ Manage 57(3): 620-636.

2. Deininger K, Jin S (2006) Tenure security and land-related investment: Evidence from Ethiopia. Eur Econ Rev 50(5): 1245-1277.

3. Zeweld W, Van Huylenbroeck G, Tesfay G, Speelman S (2017) Smallholder farmers' behavioural intentions towards sustainable agricultural practices. J Environ Manage 187: 71-81.

4. Mekuriaw A, Heinimann A, Zeleke G, Hurni H (2018) Factors influencing the adoption of physical soil and water conservation practices in the Ethiopian highlands. Int Soil Water Conserv Res 6(1): 23-30.

5. Wolka K, Sterk G, Biazin B, Negash M (2018) Benefits, limitations and sustainability of soil and water conservation structures in Omo-Gibe basin, Southwest Ethiopia. Land use policy 73: 1-10.

6. Bewket W (2007) Soil and water conservation intervention with conventional technologies in northwestern highlands of Ethiopia: Acceptance and adoption by farmers. Land use policy 24(2): 404-416.

7. Gebremedhin B, Swinton SM (2003) Land Tenure Security and Public Programs. Agric Econ 29: 69-84.

8. Asfaw D, Neka M (2017) Factors affecting adoption of soil and water conservation practices: The case of Wereillu Woreda (District), South

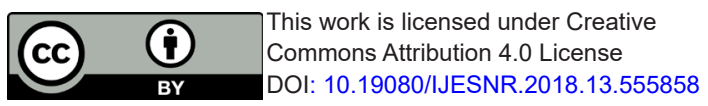

Wollo Zone, Amhara Region, Ethiopia. Int Soil Water Conserv Res 5(4): 273-279.

9. Nigussie Z, Atsushi Tsunekawa, Nigussie Haregeweyn, Enyew Adgo, Logan Cochrane, et al. (2018) Applying Ostrom's institutional analysis and development framework to soil and water conservation activities in north-western Ethiopia. Land use policy 71: 1-10.

10. Wondie M, Schneider W, Melesse AM, Teketay D (2011) Spatial and temporal land cover changes in the simen mountains national park, a world heritage Site in northwestern Ethiopia. Remote Sens 3: 752-766.

11. Karidjo BY, Wang Z, Boubacar Y, Wei C (2018) Factors influencing farmers' Adoption of Soil and Water Control Technology (SWCT) in Keita valley, a semi-arid Area of Niger. Sustain 10.

12. De Graaff J, A Amsalu, F Bodnár, A Kessler, H Posthumus, et al. (2008) Factors influencing adoption and continued use of long-term soil and water conservation measures in five developing countries. Appl Geogr 28(4): 271-280.

13. Tesfahunegn GB, Mekonen K, Tekle A (2016) Farmers perception on causes, indicators and determinants of climate change in northern Ethiopia: Implication for developing adaptation strategies. Appl Geogr 73: $1-12$.

14. Randell H, Gray C (2016) Climate variability and educational attainment: Evidence from rural Ethiopia. Glob Environ Chang 41: 111-123.

15. Pandey R, Praveen Kumar, Kelli M Archie, Ajay K Gupta, PK Joshi, et al. (2018) Climate change adaptation in the western-Himalayas: Household level perspectives on impacts and barriers. Ecol Indic 84: 27-37.

16. Lungarska A, Chakir R (2018) Climate-induced Land Use Change in France: Impacts of Agricultural Adaptation and Climate Change Mitigation. Ecol Econ 147: 134-154.

17. Greiner R, Patterson L, Miller O (2009) Motivations risk perceptions and adoption of conservation practices by farmers. Agric Syst 99(2-3): 86-104.

18. Bekele W, Drake L (2003) Soil and water conservation decision behavior of subsistence farmers in the Eastern Highlands of Ethiopia: A case study of the Hunde-Lafto area. Ecol Econ 46(3): 437-451.

19. Bunclark L, John Gowing, Elizabeth Oughton, Diane Benao, et al. (2018) Understanding farmers' decisions on adaptation to climate change: Exploring adoption of water harvesting technologies in Burkina Faso. Glob Environ Chang 48: 243-254.

20. D Souza A, Mishra AK (2018) Adoption and Abandonment of Partial Conservation Technologies in Developing Economies: The Case of South Asia. Land use policy 70: 212-223.

\section{Your next submission with Juniper Publishers will reach you the below assets}

- Quality Editorial service

- Swift Peer Review

- Reprints availability

- E-prints Service

- Manuscript Podcast for convenient understanding

- Global attainment for your research

- Manuscript accessibility in different formats

( Pdf, E-pub, Full Text, Audio)

- Unceasing customer service

Track the below URL for one-step submission https://juniperpublishers.com/online-submission.php 